\title{
Why adefovir is not yet available in Canada
}

\author{
Morris Sherman MB BCh PhD FRCPC ${ }^{1,2}$
}

$\mathrm{T}$ he introduction of lamivudine for the management of chronic hepatitis B virus (HBV) infection heralded a new era in the management of the disease. Until then, the only available therapy was interferon-alpha (IFN- $\alpha$ ), which was expensive and difficult to take. It required three injections a week for four months to two years for some forms of HBV. IFN- $\alpha$ was able to induce a response in a small proportion of patients. In hepatitis $\mathrm{B}$ e antigen ( $\mathrm{HBeAg}$ )-positive patients, seroconversion from $\mathrm{HBeAg}$ to the antibody for $\mathrm{HBe}$ (antiHBe) occurred in just over $30 \%$ of treated patients $(1,2)$. Alanine aminotransferase (ALT) normalized and HBV DNA became undetectable in serum using the insensitive assays at the time. In the anti-HBe-positive patients, the durable response of therapy was appoximately $20 \%$, again using the insensitive solution hybridization assay for HBV DNA (3-5).

Lamivudine is an oral agent with only minor side effects. The registration trials lasted one year, with a disappointing HBeAg seroconversion rate of approximately $18 \%$ to $20 \%(6)$. In the anti-HBe-positive patients, adequate viral suppression was achieved on therapy, but after withdrawal of lamivudine, more than $75 \%$ of patients relapsed $(7,8,9)$. However, suppression of viral replication could be maintained beyond the first year by continued therapy (10). This was usually associated with improved ALT levels and improved histology (11). Until recently, there was no information that lamivudine had any effect on hard end points such as survival. Last year, however, data were published showing that long-term lamivudine use in cirrhotic patients with active viral replication decreased the incidence of liver-related complications such as hepatoma, liver failure and liver-related death (12).

Lamivudine use, however, has been severely restricted by the development of resistance. In a study by Hadziyannis et al (13), within the first year of use approximately $18 \%$ of infections became resistant to lamivudine, and over four years approximately $70 \%$ of patients had developed resistance. Lamivudine resistance is associated with a rebound in the concentration of virus in serum and, usually, with an increase in ALT and histological disease progression. Initially, it was thought that the development of resistance did not affect the rate of progression of disease, but recent evidence has disproved that hypothesis $(12,14,15)$. In fact, in patients with cirrhosis who develop lamivudine-resistant infection, the rate of progression to death is rapid and this has become a feared outcome.

There are now a number of newer agents for use in HBV patients. These include adefovir $(16,17)$ and entecavir $(18,19)$, both licensed in many parts of the world but not in Canada. Other drugs in the pipeline include telbivudine, pradefovir, emtricitabine and clevudine. Although tenofovir is not licensed for HBV, it is also a potent anti-HBV drug and is available in Canada (20). It has been used to treat lamivudineresistant $\mathrm{HBV}$ infection. Adefovir was the first drug after lamivudine to be commercialized. In the United States, adefovir was first licensed in 2002. It maintains full antiviral activity in lamivudine-resistant infection, so that in addition to being used as a first-line drug, it has been used to rescue lamivudine-resistant infection (21). Adefovir resistance does occur, although at a much lower rate than lamivudine. Hadziyannis et al (13) showed that in the first year of therapy, the resistance rate was in the range of $1 \%$ to $2 \%$ and after five years, the resistance rate was approximately $28 \%$ compared with $70 \%$ for lamivudine. Although adefovir is less potent than lamivudine, it has been recommended for first-line use because of the lower rate of resistance, particularly in anti-HBe-positive chronic HBV, where treatment may have lasted for many years (22).

Adefovir has been available in the United States for more than three years. It was submitted for licensing in Canada in June 2002 and received the notice of compliance in August 2003, a little over one year later. However, more than two years later, it is still not available in Canada. The reason is that the Patented Medicines Price Review Board (PMPRB) has not allowed Gilead Sciences Inc (USA), the manufacturer, to charge the price it wishes.

The PMPRB negotiates with pharmaceutical manufacturers to set drug prices in Canada. The drugs are reviewed using several principles; if the drug is used to treat a disease for which there are existing treatments of equivalent efficacy (eg, another statin or histamine 2 receptor blocker), the price should be in the same price range as other drugs used to treat the same disease. If the drug is a breakthrough drug (eg, for a previously untreatable disease or greatly improved efficacy over existing treatments), the price charged in Canada should be no more than the median of prices charged in seven industrialized countries (USA, Italy, France, Sweden, Switzerland, United Kingdom and Germany). Gilead Sciences Inc, the makers of adefovir, sought presale advisory assistance from the PMPRB, and on the basis of that advice, decided not to proceed with marketing in Canada (recently Gilead Sciences Inc has revised its approach and is undertaking premarketing activities). The substance of these discussions is not public, but it seems that the price that the PMPRB was prepared to allow was insufficient for the manufacturer. One can only presume that the PMPRB reviewed adefovir as a 'me too' drug so that the set price would be approximately the same as for lamivudine. This was not acceptable to Gilead Sciences Inc because the cost of one month's therapy in, for example, the United States was at

${ }^{1}$ Department of Medicine, University of Toronto; ${ }^{2}$ Division of Gastroenterology, University Health Network, Toronto, Ontario

Correspondence: Dr Morris Sherman, Toronto General Hospital, 9N-981, 200 Elizabeth Street, Toronto, Ontario M5G 2C4.

Telephone 416-340-4756, fax 416-591-2107, e-mail morris.sherman@uhn.on.ca

Received for publication January 12, 2006. Accepted February 17, 2006 
least three times higher than that of lamivudine. Hence, the drug is not being sold in Canada.

Gilead Sciences Inc has, however, established an early access program that allows some physicians access to free drugs. As of November 16, 2005, 812 patients are receiving free drugs. Essentially, this is a gift on the part of Gilead Sciences Inc to Canada, the value of which (assuming on average one year of use) exceeds $\$ 5$ million.

There are several reasons why the PMPRB decision must be revisited. Although we have no data, there must be thousands of patients with chronic HBV who have been treated with lamivudine since it was first licensed in approximately 1998. For $70 \%$ of those patients, long-term therapy is required and in approximately $70 \%$ of that proportion, lamivudine resistance must have developed. Thus, these patients are either without treatment or are continuing to take treatment that is ineffective. For those patients who were cirrhotic at the start of therapy (an unknown proportion), the risk of hepatic decompensation is high. These patients can be rescued with adefovir and if maintained on both adefovir and lamivudine, they may have a low likelihood of developing further resistance (at least over the first few years).

It is scandalous that the drug approval process in Canada is so slow. It took 13 months to review the data and approve the drug. Pegylated IFN- $\alpha$-2a plus ribavirin for hepatitis C took three years to be approved. This is not acceptable. In the United States, the review process takes six months. Why it is necessary in Canada to repeat the review previously performed elsewhere is inexplicable. There is no need to reinvent the wheel. Both the Food and Drug Administration (FDA) and European agencies undertake extremely detailed and critical reviews. A look at the FDA website for any particular drug clearly shows the depth of the analysis. Health Canada does not provide details of the review process so it is not possible to assess the details of the review, but it is surely unnecessary to repeat what the FDA and the Europeans have done.

In the case of adefovir, the delay in access is particularly ironic because many of the patients who were studied in the registration trials came from Canada. Prominent Canadian hepatologists, Dr Jenny Heathcote in particular, played an important role in the development of this drug. Yet, it is still not available here.

In addition, the PMPRB review has been conducted in ignorance of the importance of adefovir. There are no hepatologists, infectious disease experts nor anyone who can provide informed advice on the board. No external consultations with such experts appear to have been undertaken. When questioned about the decision, the chairwoman of the board

\section{REFERENCES}

1. Perrillo RP, Schiff ER, Davis GL, et al A randomized, controlled trial of interferon alfa-2b alone and after prednisone withdrawal for the treatment of chronic hepatitis B. The Hepatitis Interventional Therapy Group. N Engl J Med 1990;323:295-301.

2. Wong DK, Cheung AM, O'Rourke K, Naylor CD, Detsky AS, Heathcote J. Effect of alpha-interferon treatment in patients with hepatitis B e antigen-positive chronic hepatitis B. A meta-analysis. Ann Intern Med 1993;119:312-23.

3. Manesis EK, Hadziyannis SJ. Interferon alpha treatment and retreatment of hepatitis $\mathrm{B}$ e antigen-negative chronic hepatitis $\mathrm{B}$. Gastroenterology 2001;121:101-9.

4. Lampertico P, Del Ninno E, Vigano M, et al. Long-term suppression of hepatitis B e antigen-negative chronic hepatitis B by 24-month interferon therapy. Hepatology 2003;37:756-63. indicated that Gilead Sciences Inc was indeed free to sell adefovir and could charge whatever price they chose. However, Gilead Sciences Inc would have to refund the difference between the approved price and the actual price. This is a disingenuous answer designed to absolve the board of responsibility for the lack of availability of adefovir. After an initial protest against the decision by some hepatologists and by the Canadian Liver Foundation (Toronto, Ontario), the PMPRB contacted Gilead Sciences Inc for further discussions, the outcome of which is unknown.

Between them, Health Canada and the PMPRB have, through ignorance and inefficiency, created a situation in which a valuable drug is not available to Canadians who need it; patients for whom there is no other drug substitute. In my practice alone, there has been serious morbidity, and elsewhere, quite likely some deaths because adefovir was not available. It is particularly hard to swallow this decision, given that trastuzumab (Herceptin, Hoffmann-La Roche Ltd, Canada), at more than $\$ 100,000$ for a one-year course, has been granted pricing approval. Other equally expensive drugs for HIV are also available (eg, tenofovir).

This is a situation that must be remedied. There are additional HBV drugs coming. They will likely also be expensive. However, as with HIV, we need to have an armamentarium of different drugs with different resistance profiles available to provide to our patients if and when resistance to current therapy emerges. In the near future, we will be using combination therapy rather than monotherapy and again will need to be able to select from a pool of available drugs, depending on preexisting resistance profiles. Entecavir will be the next agent up for consideration. If the same principles are applied by the PMPRB, this drug will not receive pricing approval either. Yet, entecavir is the most powerful drug in its class (23). It has the best antiviral effect and the best resistance profile so far. This in itself will make it a valuable drug. We cannot wait another four to five years for entecavir to become available.

The PMPRB should be pressured to reconsider the pricing of adefovir and to do so with some urgency. Indeed, the whole drug review process in Canada needs to improve.

The views expressed in the article are the personal views of the author and do not necessarily reflect the views of either the Canadian Association for the Study of the Liver or Pulsus Group Inc.

Dr Sherman is on the advisory boards of Gilead Sciences Inc in Canada, Roche Canada and Bristol Myers Squibb, and has given sponsored talks for Roche and Bristol Myers Squibb.

5. Brunetto MR, Oliveri F, Coco B, et al. Outcome of anti-HBe positive chronic hepatitis $B$ in alpha-interferon treated and untreated patients: A long term cohort study. J Hepatol 2002;36:263-70.

6. Schalm SW, Heathcote J, Cianciara J, et al. Lamivudine and alpha interferon combination treatment of patients with chronic hepatitis B infection: A randomized trial. Gut 2000;46:562-8.

7. Tassopoulos NC, Volpes R, Pastore G, et al. Efficacy of lamivudine in patients with hepatitis B e antigen-negative/ hepatitis B virus DNA-positive (precore mutant) chronic hepatitis B. Lamivudine Precore Mutant Study Group. Hepatology 1999;29:889-96.

8. Santantonio T, Mazzola M, Iacovazzi T, Miglietta A, Guastadisegni A, Pastore G. Long-term follow-up of patients 
with anti-HBe/HBV DNA-positive chronic hepatitis B treated for 12 months with lamivudine. J Hepatol 2000;32:300-6

9. Hadziyannis SJ, Papatheodoridis GV, Dimou E, Laras A, Papaioannou C. Efficacy of long-term lamivudine monotherapy in patients with hepatitis $\mathrm{B}$ e antigen-negative chronic hepatitis $\mathrm{B}$. Hepatology 2000;32:847-51.

10. Fung SK, Wong F, Hussain M, Lok AS. Sustained response after a 2-year course of lamivudine treatment of hepatitis $\mathrm{B}$ e antigen-negative chronic hepatitis B. J Viral Hepat 2004;11:432-8.

11. Leung NWY, Lai CL, Chang TT, et al. Extended lamivudine treatment in patients with chronic hepatitis B enhances hepatitis B e antigen seroconversion rates: Results after 3 years of therapy. Hepatology 2001;33:1527-32.

12. Liaw YF, Sung JJ, Chow WC, et al. Lamivudine for patients with chronic hepatitis B and advanced liver disease. N Engl J Med 2004;351:1521-31.

13. Hadziyannis S, Tassopoulos N, Chang TT, et al. Long term adefovir dipivoxil treatment induces regression of liver fibrosis in patients with $\mathrm{HBeAg}$ negative chronic hepatitis B: Results after 5 years of therapy. Hepatology 2005;43(Suppl 1):755.

14. Di Marco V, Di Stefano R, Ferraro D, et al. HBV-DNA suppression and disease course in HBV cirrhosis patients on long-term lamivudine therapy. Antivir Ther 2005;10:431-9.

15. Andreone P, Gramenzi A, Cursaro C, et al. High risk of hepatocellular carcinoma in anti-HBe positive liver cirrhosis patients developing lamivudine resistance. J Viral Hepat 2004;11:439-42.
16. Marcellin P, Chang TT, Lim SG, et al. Adefovir dipivoxil for the treatment of hepatitis $\mathrm{B}$ e antigen-positive chronic hepatitis B. N Engl J Med 2003;348:808-16.

17. Hadziyannis SJ, Tassopoulos NC, Heathcote EJ, et al. Adefovir dipivoxil for the treatment of hepatitis $\mathrm{B}$ e antigen-negative chronic hepatitis B. N Engl J Med 2003;348:800-7.

18. Chang TT, Gish, R, de Man R, et al. Entecavir is superior to lamivudine for the treatment of HBeAg + ve chronic hepatitis B: Results of Phase III study ETV-022 in nucleoside naive patients. Hepatology 2004; 40(Suppl 1):193A. (Abst)

19. Shouval D, Lai CL, Cheinquer H, et al. Entecavir demonstrates superior histologic and virologic efficacy over lamivudine in nucleoside-naïve HBEAG-ve chronic hepatitis B: Results of phase III trial ETV 027. Hepatology 2004;40(Suppl 1):73.

20. van Bommel F, Wunsche T, Mauss S, et al. Comparison of adefovir and tenofovir in the treatment of lamivudine-resistant hepatitis B virus infection. Hepatology 2004;40:1421-5.

21. Schiff ER, Lai CL, Hadziyannis S, et al. Adefovir dipivoxil therapy for lamivudine-resistant hepatitis B in pre- and post-liver transplantation patients. Hepatology 2003;38:1419-27.

22. Keeffe EB, Dieterich DT, Han SH, et al. A treatment algorithm for the management of chronic hepatitis B virus infection in the United States. Clin Gastroenterol Hepatol 2004;2:87-106.

23. Dienstag JL, Wei LJ, Xu D, Cross A, Kreter B, Wilber R. Entecavir is superior to lamivudine and adefovir in trials of HBeAg-positive and negative hepatitis B infection: A cross-study analysis with published reports. J Hepatol 2005:42(Suppl 2):174. 


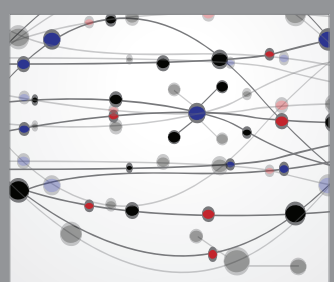

The Scientific World Journal
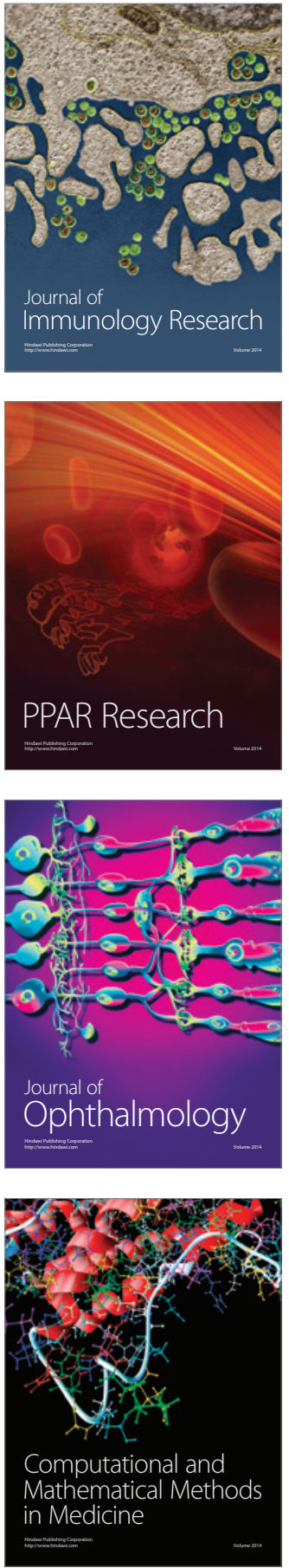

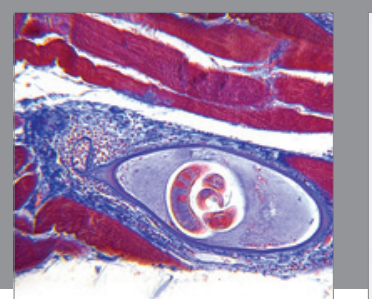

Gastroenterology Research and Practice

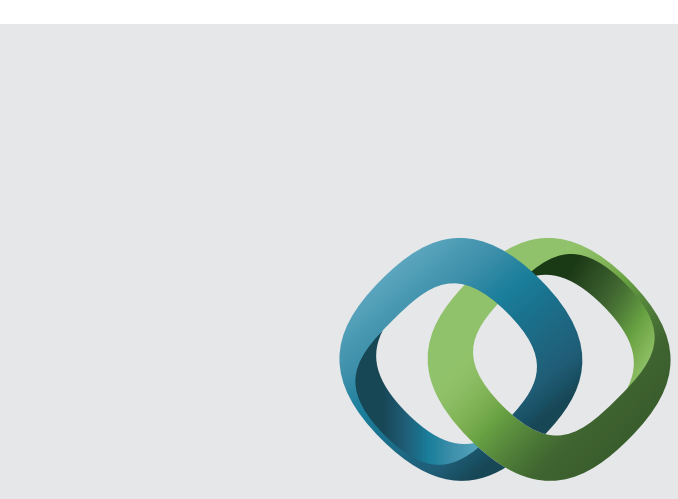

\section{Hindawi}

Submit your manuscripts at

http://www.hindawi.com
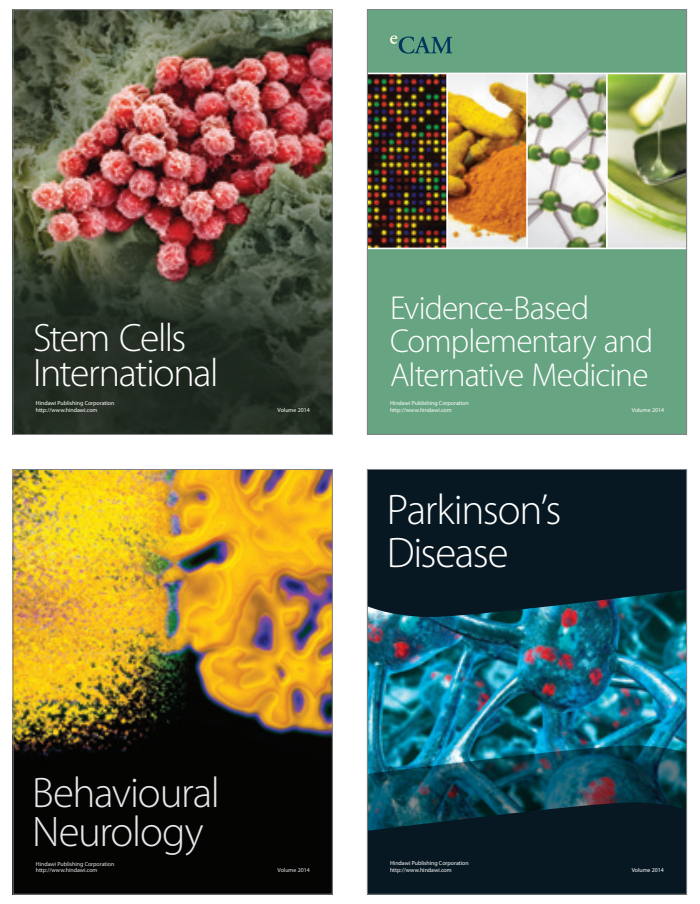
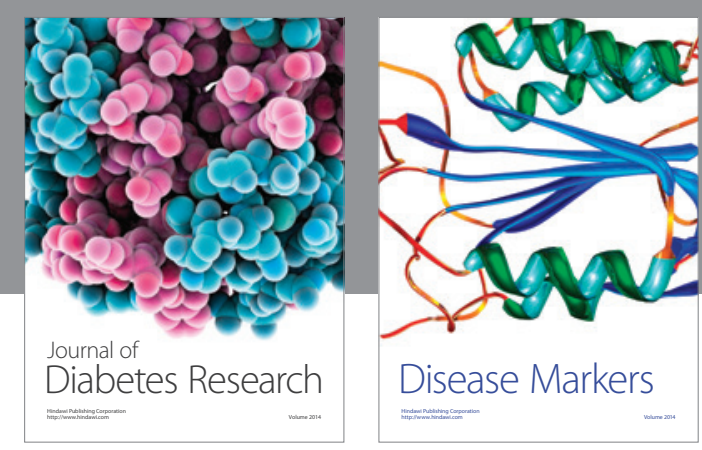

Disease Markers
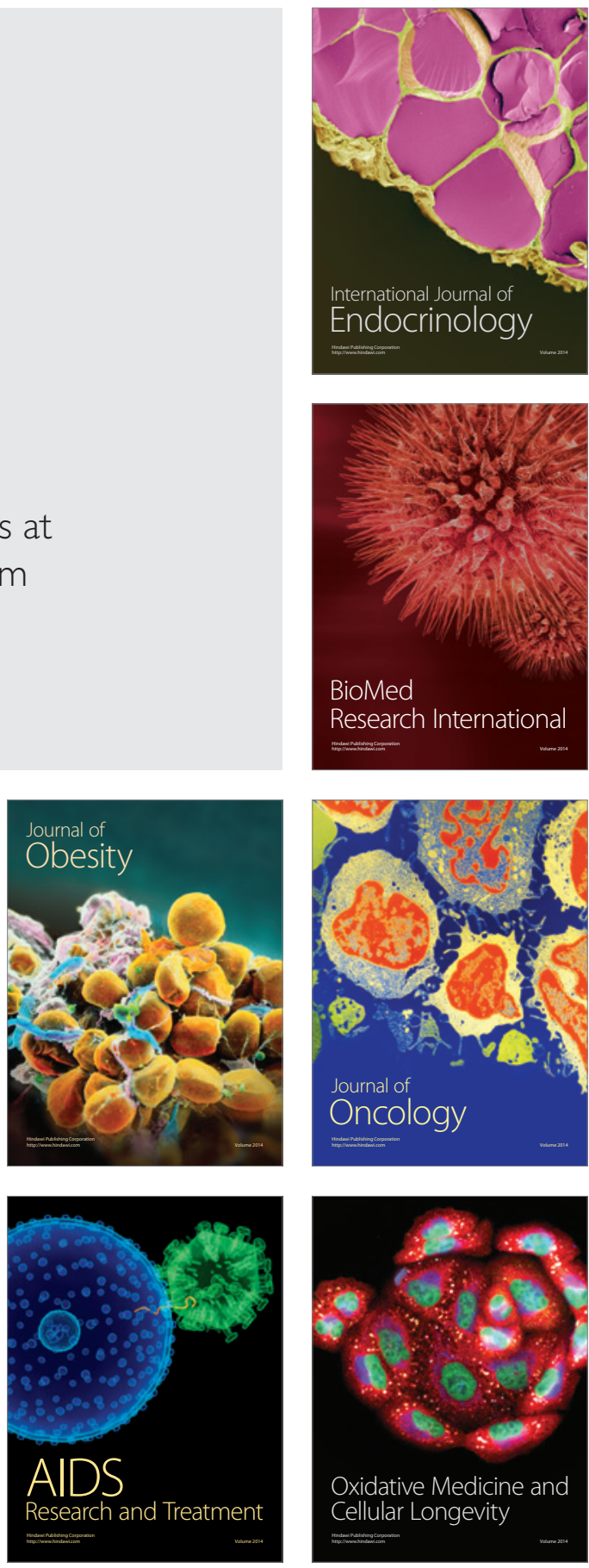